\title{
Transfer of Muscle Strength Between Single-Joint and Multi-Joint Exercises for Lower Limbs
}

\author{
Tereza Hammerová', Jan Chlápek, Tereza Králová', \\ Tomáš Vodička' , Zuzana Hlavoňová', Jan Ondráček'
}

1 Faculty of Sports Studies, Masaryk University

\begin{abstract}
Most strength and conditioning coaches deal with the question in the training plan, how to supplement specific exercises, or which non-specific exercises would be the most suitable for achieving the set purpose. This study aims to assess what strength transfer with a focus on the lower limbs is projected from the selected strength intervention program (the right leg exercises only single-joint exercises: leg extension on machine and leg curl; the left leg exercises only multi-joint exercises: deadlift and leg press) to the force of the knee joint flexors and extensors during the eccentric and the concentric contraction. In one training session, the participants repeated every exercise five times in four series. The load intensity was around $90 \%$ of 1 RM and was increased by $5 \%$ after the first and the fifth week. The rest interval was always three minutes long. For the left lower limb, the highest transfer (0.20) was from the leg press to the knee joint extensor at the eccentric contraction and from the deadlift was the highest transfer (0.19) to the knee joint extensor at the eccentric contraction. For the right lower limb, the highest transfer (0.53) was from the leg extension on a machine to the knee joint flexor at the concentric contraction and from the lying leg curl was the highest transfer (0.47) to the knee joint flexor at the concentric contraction.
\end{abstract}

Keywords: Multi-Joint Exercises, Single-Joint Exercises, Transfer of Muscle Strength, Extensors and Flexors of Knee Joint

\section{INTRODUCTION}

Due to the ever-increasing sports competition, the trainer must consider what non-specific exercises will complement their fitness training plan. Training transfer decides which exercises are useful for athletic performance and which are useless (Issurin, 2013). The choice of exercises could be influenced by the knowledge of transfers from non-specific exercises to specific exercises. This study will focus on strength abilities.

Strength, or strength ability, is a fitness movement ability of an individual, manifested by overcoming, holding or inhibiting a certain resistance (Dovalil et al, 2005). Strength abilities can be viewed from the perspective of muscle contraction. Muscle contractions are differentiated by muscle length and muscle tension. In isometric contraction, tension increases, but muscle length does not change. In isotonic contraction, muscle length varies, but the tension remains approximately the same (the concentric contraction /CON/ - muscle shortens, the eccentric contraction /ECC/ - muscle extends) (Perič, \& Dovalil, 2010).

Exercises used to develop strength can be divided into single-joint exercises and multi-joint exercises. Single-joint (SJ) exercises are considered to be exercises where the movement is performed in only one joint with a focus on one muscle/muscle group (Stoppani, 2016). Multi-joint $/ \mathrm{MJ}$ / exercises are those exercises that involve more joints and more muscle/muscle groups in the exercise, which better reflect the daily movement. For example, research Gentil, Fisher, \& Steele 
(2017) comparing the two groups (MJ, MJ + SJ) concluded that adding a single-joint exercise to multi-joint exercises program does not increase muscle size and muscle strength.

The increase in strength can be achieved in different ways of training. The effect of transfer from one exercise to another, although very similar in performance (for example, from squat to half-squat or leg press), is always significantly lower than from a specific exercise (Zatsiorsky \& Kraemer, 2014). The rate of transfer can be determined by the amount of resistance, speed of an exercise, muscle activation, mechanical movement parameters, and energy coverage. To be able to compare the individual performances directly in different exercises, Zatsiorsky \& Kraemer $(2014$, p. 27) introduce a unit of performance increase expressed in standard deviations:

$$
\text { Result gain }=\frac{\text { Gain of performance }}{\text { Standard deviation of performance }} .
$$

If the average strength of the group is $60 \pm 10 \mathrm{~kg}$ (average \pm standard deviation) and the athletes improve by $15 \mathrm{~kg}$ in performance after the training, the athletes achieve an improvement of $15 / 10$ or 1.5 standard deviations.

For transfer evaluation, we consider the ratio of performance improvement in untrained and trained exercises. We define the transfer coefficient of the training as follows:

$$
\text { Transfer }=\frac{\text { Result gain in nontrained exercise }}{\text { Result gain in trained exercise }} \text {, Zatsiorsky \& Kraemer (2014, p. 27). }
$$

Intervention program including both single-joint exercises (leg extension on the machine, lying leg curl) and multi-joint exercises (deadlift, leg press) was applied by Jan Chlápek (2019) in his research. He evaluated the $1 \mathrm{RM}$ and isokinetic dynamometer data as follows:

All exercises (leg extension on the machine, lying leg curl, deadlift and leg press) show statistically significant differences $(\mathrm{p}<0.05)$ of $1 \mathrm{RM}$ values between pretest and posttest measurements based on parametric paired t-test. Strength intervention had a positive effect on the increase of $1 \mathrm{RM}$ values in all exercises (Chlápek, 2019).

Chlápek (2019) compares testing on an isokinetic dynamometer considering extensors and flexors of the knee joint and considering the concentric and the eccentric muscular activity. During the concentric muscle activity, the muscle force of the knee joint extensors and flexors was significantly improved as a result of the strength intervention $(\mathrm{p}<0.05)$. However, there was no statistically significant difference between the left and right lower limbs before or after the intervention ( $p>0.05)$. During the eccentric muscle activity, the muscle force of the knee joint extensors and flexors was significantly improved as a result of the strength intervention $(\mathrm{p}<$ $0.05)$. However, there was no statistically significant difference between the left and right lower limbs before or after the intervention ( $\mathrm{p}>0.05)$ (Chlápek, 2019).

The question remains of how the change in $1 \mathrm{RM}$ values is related to the change in the values obtained from the isokinetic dynamometer.

\section{METHODS}

All original data were obtained in a research conducted by Tereza Králová and Jan Chlápek to create a thesis (Effects of isolated and compound exercises on the strength) by Jan Chlápek and to create this article. 


\section{Subjects}

The test sample consisted of 10 male students of the Faculty of Sports Studies of Masaryk University. The average age of the group was $24,7( \pm 0,94)$ years, average body height was 179,9 $( \pm 8,00) \mathrm{cm}$ and average body weight was 78,9 $( \pm 9,21) \mathrm{kg}$ (Chlápek, 2019).

\section{Study design}

For this study, measurement 1RM (repetition maximum) and measurement on isokinetic dynamometer were essential. Both measurements were performed both before (pretest) and after (posttest) the strength intervention program.

$1 \mathrm{RM}$ was measured for the following exercises:

$\checkmark$ for the right leg, single-joint exercises:

- leg extension in the knee joint on a machine while sitting (hereafter referred to as leg extension on a machine),

- leg curl (while lying),

for the left leg, multi-joint exercises:

- deadlift

- and leg press.

1RM was always measured for the specific lower limb and according to the Baechle (2008) protocol.

An isokinetic dynamometer (Humac Norm CSMI (Stoughton, USA)) was used to test lower limb force. Both the pretest and the posttest measurements were carried out in a sitting position, focusing on the knee joint flexors and extensors. First, the right and then the left leg was measured. The range of motion was set to 90 degrees at an angular velocity of $60^{\circ} \cdot \mathrm{s}^{-1}$. The subjects were banded with fixation bands to avoid the involvement of other muscle groups. The force of the selected muscles of the lower limbs was measured in the following order: first, the concentric extension and the concentric flexion, followed by rest and the eccentric extension and the eccentric flexion (Chlápek, 2019, p. 34).

The protocol (Figure 1) gives us the sequence and the most important information of the selected measurements and the intervention strength program.

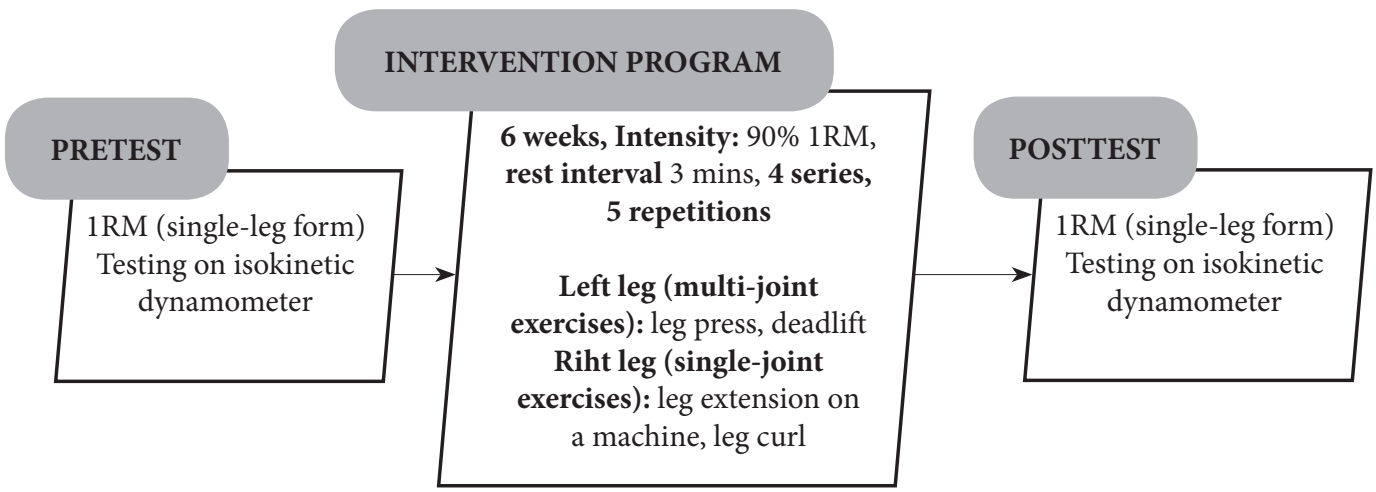

Fig. 1: Diagram of measurements and intervention program 
Before all measurements, the subjects were properly warmed up and instructed to avoid possible injury.

The six-week intervention strength program was carried out as well as all tests of research at the Faculty of Sports Studies of Masaryk University. There was a 48-hour rest period between each intervention. To be a progressive load all the time, we increased the load by $5 \%$ after the first and the fifth week. The intervention program was focused on the single-leg form exercises. Test subjects loaded the right leg for single-joint exercises all the time and the left leg for multijoint exercises ( 2 exercises for each method). The exercise intensity (90\% 1RM), rest interval (3 mins), number of series (4 times) and number of repetitions (5 times) were identical in both methods (Chlápek, 2019).

The purpose of the study was to find out the effect size of the transfer of strength abilities from single-joint exercises and multi-joint exercises to the force of the knee joint extensors and flexors during both the concentric and the eccentric work measured on an isokinetic dynamometer.

\section{Statistical analysis}

The data were evaluated according to formulas for calculating the transfer from Zatsiorsky \& Kraemer (2014) and Microsoft Excel was used afterwards.

\section{Results}

Transfer is always calculated from a specific exercise of intervention program (leg press, deadlift, leg extension on a machine, leg curl) to the isokinetic force of the knee joint muscles (flexors, extensors) during various muscular activities (the concentric, the eccentric). We compare the effect of strength progression [1RM] on an isokinetic force of muscle [Nm].

\section{Transfer}

First, we will focus on the results of the left lower limb that has been practicing multi-joint exercises during the intervention program. In the leg press exercise, the transfer of strength abilities was following: the highest transfer was for extensor force at the eccentric contraction $(0.20)$, then for flexor force at the concentric contraction (0.19), then for extensor force at the concentric contraction (0.17) and the lowest transfer $(0.13)$ was for flexor force at the eccentric contraction (Table 1). In the deadlift exercise, the transfer of strength abilities was following: the highest transfer was for the extensor force at the eccentric contraction (0.19), then for the flexor force at the concentric contraction (0.18), then for the extensor force at the concentric contraction $(0.16)$ and the lowest transfer $(0.12)$ was for flexor force at the eccentric contraction (Table 1$)$. 
Tab. 1: The transfer from leg press and deadlift

\begin{tabular}{|c|c|c|c|c|c|}
\hline \multicolumn{6}{|c|}{ LEFT LEG } \\
\hline TEST & PRETEST & POSTTEST & $\begin{array}{c}\text { GAIN OF } \\
\text { PERFORMANCE }\end{array}$ & RESULT GAIN & TRANSFER \\
\hline \multicolumn{6}{|c|}{ LEFT LEG (LEG PRESS SINGLE-LEG, DEADLIFT SINGLE-LEG) } \\
\hline $\begin{array}{l}\text { LEG PRESS } \\
\text { Strength [kg] }\end{array}$ & $91.5 \pm 19.59$ & $111.5 \pm 21.25$ & $20.0 \pm$ Std.Dev. & $20.0: 19.59=1.02$ & \\
\hline $\begin{array}{l}\text { Force } \\
{[\mathrm{Nm}] \mathrm{CON}} \\
\text { EXTENSORS }\end{array}$ & $217.8 \pm 46.78$ & $225 \pm 43.07$ & $8.0 \pm$ Std.Dev. & $8.0: 46.78=0.17$ & $0.17: 1.02=0.17$ \\
\hline $\begin{array}{l}\text { Force }[\mathrm{Nm}] \\
\text { CON FLEXORS }\end{array}$ & $126.5 \pm 23.17$ & $130.9 \pm 28.80$ & $4.4 \pm$ Std.Dev. & $4.4: 23.17=0.19$ & $0.19: 1.02=0.19$ \\
\hline $\begin{array}{l}\text { Force } \\
{[\text { Nm] ECC }} \\
\text { EXTENSORS }\end{array}$ & $243.7 \pm 63.70$ & $256.6 \pm 58.10$ & $12.9 \pm$ Std.Dev & $12,9: 63,7=0.20$ & $0.20: 1.02=0.20$ \\
\hline $\begin{array}{l}\text { Force }[\mathrm{Nm}] \\
\text { ECC FLEXORS }\end{array}$ & $146.2 \pm 38.56$ & $151.1 \pm 37.03$ & $4.9 \pm$ Std.Dev. & $4.9: 38.56=0.13$ & $0.13: 1.02=0.13$ \\
\hline $\begin{array}{l}\text { DEADLIFT } \\
\text { Strength [kg] }\end{array}$ & $70.0 \pm 12.91$ & $84.0 \pm 13.9$ & $14.0 \pm$ Std.Dev. & $14.0: 12.91=1.08$ & \\
\hline $\begin{array}{l}\text { Force } \\
{[\mathrm{Nm}] \mathrm{CON}} \\
\text { EXTENSORS }\end{array}$ & $217.8 \pm 46.78$ & $225 \pm 43.07$ & $8.0 \pm$ Std.Dev. & $8.0: 46.78=0.17$ & $0.17: 1.08=0.16$ \\
\hline $\begin{array}{l}\text { Force }[\mathrm{Nm}] \\
\text { CON FLEXORS }\end{array}$ & $126.5 \pm 23.17$ & $130.9 \pm 28.80$ & $4.4 \pm$ Std.Dev. & $4.4: 23.17=0.19$ & $0.19: 1.08=0.18$ \\
\hline $\begin{array}{l}\text { Force } \\
{[\text { Nm] ECC }} \\
\text { EXTENSORS }\end{array}$ & $243.7 \pm 63.70$ & $256.6 \pm 58.10$ & $12.9 \pm$ Std.Dev. & $12.9: 63.7=0.20$ & $0.20: 1.08=0.19$ \\
\hline $\begin{array}{l}\text { Force }[\mathrm{Nm}] \\
\text { ECC FLEXORS }\end{array}$ & $146.2 \pm 38.56$ & $151.1 \pm 37.03$ & $4.9 \pm$ Std.Dev. & $4.9: 38.56=0.13$ & $0.13: 1.08=0.12$ \\
\hline
\end{tabular}

The values can be interpreted as percentages. It can be argued that the inclusion of the leg press exercise in the intervention program had a $20 \%$ transfer to extensor force during the eccentric work, a $19 \%$ transfer to flexor force during the concentric work, a $17 \%$ transfer to extensor force during the concentric work, and a $13 \%$ transfer to flexor force during the eccentric work. We can also say that the inclusion of deadlift exercise in the intervention program had a $19 \%$ transfer to the extensor force during the eccentric work, and $18 \%$ transfer to the flexor force during the concentric work, a $16 \%$ transfer to the extensor force during the concentric work, and a $12 \%$ transfer to the flexor force during the eccentric work.

The right lower limb practiced single-joint exercises during the intervention program. In the leg extension on a machine exercise, the transfer of strength abilities was following: the highest transfer $(0.53)$ was for flexor force at the concentric contraction, then for flexor force at the eccentric contraction (0.46), then for extensor force at the eccentric contraction $(0.40)$ and the lowest transfer (0.34) was for extensor force at the concentric contraction (Table 2). In the 
leg curl exercise, the transfer of force abilities was following: the highest transfer (0.47) was for flexor force at the concentric contraction, then for flexor force at the eccentric contraction $(0.40)$, then for extensor force at the eccentric contraction $(0.35)$ and the lowest transfer $(0.30)$ was for extensors force at the concentric contraction (Table 2).

Tab. 2: The transfer from leg extension on machine and leg curl

\begin{tabular}{|c|c|c|c|c|c|}
\hline \multicolumn{6}{|c|}{ RIGHT LEG } \\
\hline TEST & PRETEST & POSTTEST & $\begin{array}{c}\text { GAIN OF } \\
\text { PERFORMANCE }\end{array}$ & RESULT GAIN & TRANSFER \\
\hline \multicolumn{6}{|c|}{ RIGHT LEG (LEG EXTENSION ON MACHINE SINGLE-LEG, LEG CURL SINGLE-LEG) } \\
\hline $\begin{array}{l}\text { LEG EXTENSION } \\
\text { ON A MACHINE } \\
\text { Strength [kg] }\end{array}$ & $30.0 \pm 5.89$ & $35.95 \pm 8.74$ & $5.95 \pm$ Std.Dev. & $5.95: 5.89=1.01$ & \\
\hline $\begin{array}{l}\text { Force }[\mathrm{Nm}] \\
\text { CON } \\
\text { EXTENSORS }\end{array}$ & $226.3 \pm 40.07$ & $239.9 \pm 38.45$ & $13.6 \pm$ Std.Dev. & $13.6: 40.07=0.34$ & $0.34: 1.01=0.34$ \\
\hline $\begin{array}{l}\text { Force }[\mathrm{Nm}] \\
\text { CON FLEXORS }\end{array}$ & $128 \pm 23.80$ & $140.9 \pm 27.00$ & $12.9 \pm$ Std.Dev. & $12.9: 23.8=0.54$ & $0.54: 1.01=0.53$ \\
\hline $\begin{array}{l}\text { Force }[\mathrm{Nm}] \\
\text { ECC EXTENSORS }\end{array}$ & $252.2 \pm 57.79$ & $275.2 \pm 54.05$ & $23 \pm$ Std.Dev. & $23.0: 57.79=0.40$ & $0.40: 1.01=0.40$ \\
\hline $\begin{array}{l}\text { Force }[\mathrm{Nm}] \\
\text { ECC FLEXORS }\end{array}$ & $137.4 \pm 38.05$ & $155 \pm 40.39$ & $17.6 \pm$ Std.Dev. & $17.6: 38.05=0.46$ & $0.46: 1.01=0.46$ \\
\hline $\begin{array}{l}\text { LEG CURL } \\
\text { Strength [kg] }\end{array}$ & $25.5 \pm 7.15$ & $33.65 \pm 10.71$ & $8.15 \pm$ Std.Dev. & $8.15: 7.15=1.14$ & \\
\hline $\begin{array}{l}\text { Force }[\mathrm{Nm}] \\
\text { CON } \\
\text { EXTENSORS }\end{array}$ & $226.3 \pm 40.07$ & $239.9 \pm 38.45$ & $13.6 \pm$ Std.Dev. & $13.6: 40.07=0.34$ & $0.34: 1.14=0.30$ \\
\hline $\begin{array}{l}\text { Force }[\mathrm{Nm}] \\
\text { CON FLEXORS }\end{array}$ & $128 \pm 23.80$ & $140.9 \pm 27.00$ & $12.9 \pm$ Std.Dev. & $12.9: 23.8=0.54$ & $0.54: 1.14=0.47$ \\
\hline $\begin{array}{l}\text { Force }[\mathrm{Nm}] \\
\text { ECC EXTENSORS }\end{array}$ & $252.2 \pm 57.79$ & $275.2 \pm 54.05$ & $23 \pm$ Std.Dev. & $23.0: 57.79=0.40$ & $0.40: 1.14=0.35$ \\
\hline $\begin{array}{l}\text { Force }[\mathrm{Nm}] \\
\text { ECC FLEXORS }\end{array}$ & $137.4 \pm 38.05$ & $155 \pm 40.39$ & $17.6 \pm$ Std.Dev. & $17.6: 38.05=0.46$ & $0.46: 1.14=0.40$ \\
\hline
\end{tabular}

The inclusion of leg extension on a machine to the intervention program caused $53 \%$ transfer to flexor force during the concentric work, $46 \%$ transfer to flexor force during the eccentric work, $40 \%$ transfer to extensor force during the eccentric work and $34 \%$ transfer to extensor force during the concentric work. The inclusion of the leg curl exercise to the intervention program caused $47 \%$ transfer to the flexor force during the concentric work, $40 \%$ transfer to the flexor force during the eccentric work, 35\% transfer to the extensor force during the eccentric work, and $30 \%$ transfer to the extensor force during the concentric work. 
Overall, it can be argued that the highest transfer of strength (0.53) was manifested in the flexor force of the right lower limb, which was measured during the concentric work. This result was achieved when calculating the transfer from $1 \mathrm{RM}$ of leg extension on a machine to flexor force at the concentric work (isokinetic dynamometer). However, it should be remembered that the right lower limb practiced both leg extension on machine and leg curl throughout the intervention program.

The lowest strength transfer (0.12) was seen in the flexor force of the left lower limb, measured during the eccentric work. This result occurred when calculating the transfer from $1 \mathrm{RM}$ of the deadlift to flexor force during the eccentric work (isokinetic dynamometer). However, the left lower limb practiced both deadlift and leg press throughout the intervention program.

\section{Increase in power expressed as a percentage}

An increase in power in percent is reported by Chlápek (2019), rounded to integers without graphical representation. The presented numerical values were recalculated separately for this study.

The influence of training can also be judged by the percentage increase in strength. Looking at changes in $1 \mathrm{RM}$ values in individual exercises, we can say that the greatest progression [kg] was achieved in the leg curl (right leg) exercise, where 1RM improved by an average of $31.96 \%$. Then 1 RM improved on average by $21.86 \%$ for leg press exercise (left leg), by $20 \%$ for deadlift (left leg) exercise, and by $19.83 \%$ for leg extension on a machine (right leg) exercise (Figure 2).

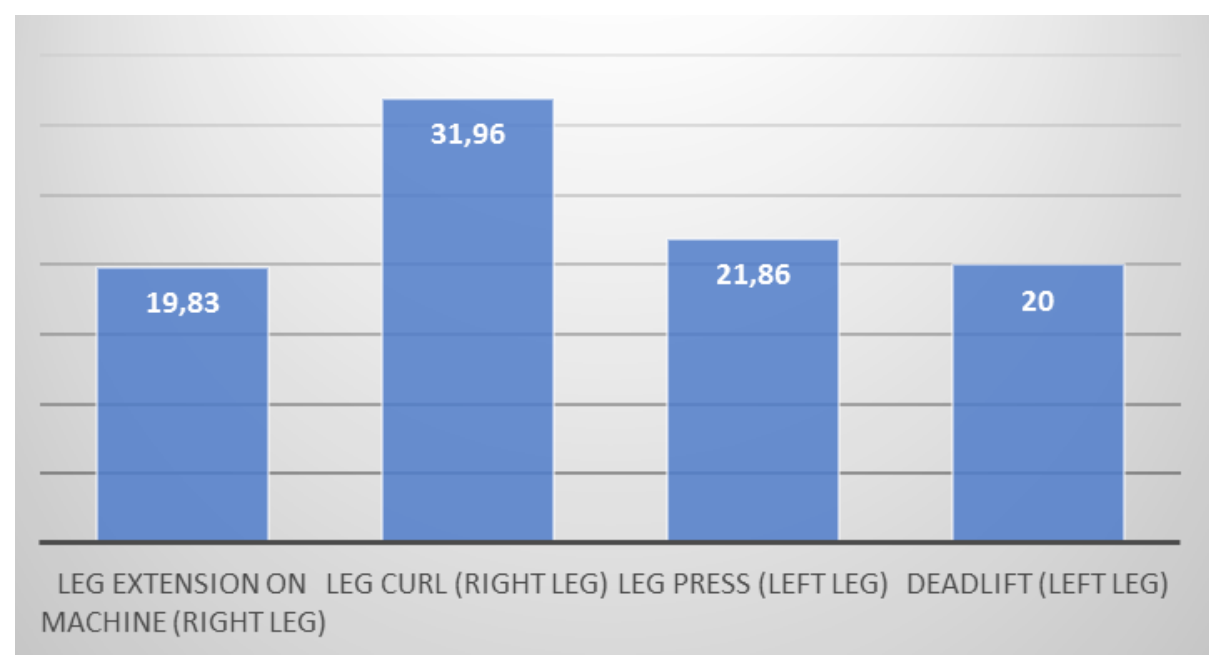

Fig. 2: Gain strength (1RM)

The change in force can also be judged by results from an isokinetic dynamometer. The greatest improvement was achieved by right knee joint flexors during the eccentric contraction, where the force improved by $12.81 \%$. The results for the right leg are following: knee joint flexors during the concentric contraction improved by $10.08 \%$, knee joint extensors during the eccentric contraction by $9.12 \%$, knee joint extensors during the concentric contraction by $6.01 \%$. The results for the left leg are following: knee joint extensors during the eccentric contraction improved by $5.29 \%$, knee joint flexors during the concentric contraction by $3.48 \%$, knee joint flexors during the eccentric contraction by $3.35 \%$, and knee joint extensors during the concentric contraction by $3.31 \%$ (Figure 3 ). 


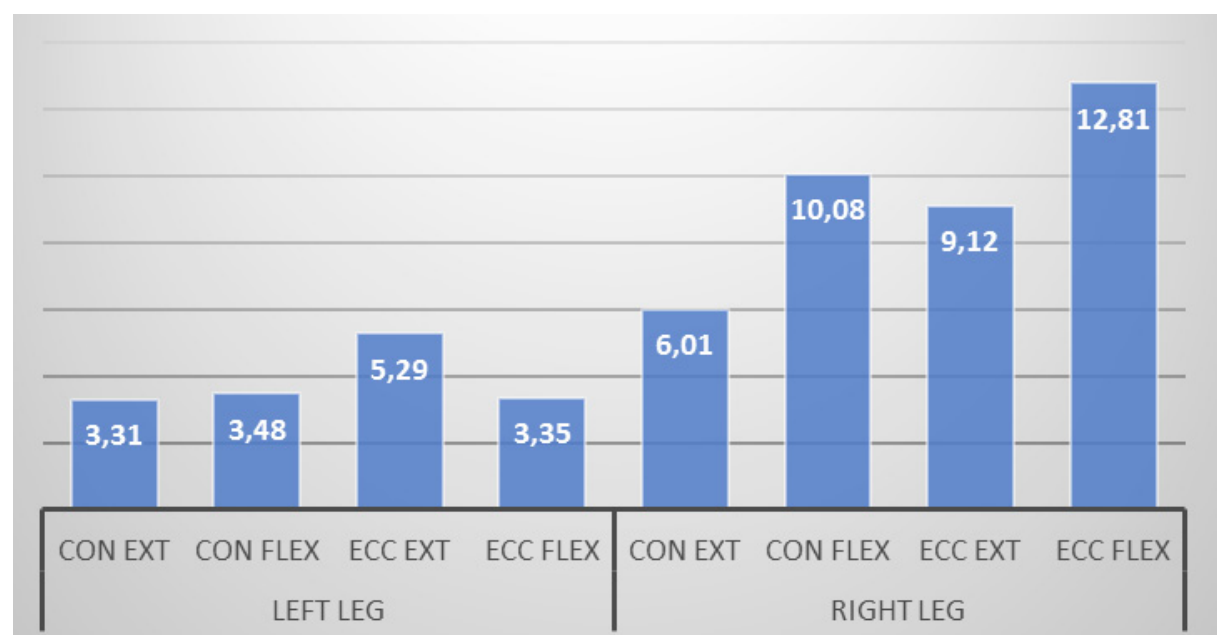

Fig. 3: Gain force (Nm)

\section{DISCUSSION}

The intervention program for left leg included deadlift and leg press. In the leg press exercise, the quadriceps, the knee extensor, is the dominant muscle (Evans, 2017; Delavier, 2015). Therefore, the highest transfer is expected for it, primarily during the concentric contraction. The highest transfer was to extensors during the eccentric contraction (0.20).

For the deadlift exercise, we assume the highest transfer to hamstring strength, knee flexor, due to the character of the exercise (Evans, 2017). In this case, the highest transfer was from deadlift to extensor force at the eccentric contraction (0.19). In both cases, we have to remember that we did not have a special experimental group for leg press exercise and a special group for deadlift, but there was only one group that practiced both exercises for the entire duration of the intervention program within the lower left limb. The result of the transfer does not correspond to the presumption probably because the deadlift exercises were also trained with heavy load (90-95\% of $1 \mathrm{RM}$ ) and due to the character of the exercises, quadriceps were more strongly activated.

The intervention program for right leg included leg extension exercises on a machine and lying leg curl. When calculating the transfer from leg extension on a machine to muscle strength, we would assume that the most prominent values will be in the quadriceps during the concentric contraction (knee joint extensor) that is dominant in the exercise (Evans, 2017, Delavier, 2015). However, the highest transfer (0.53) was seen in knee joint flexors (with the concentric contraction). This can be influenced by the fact that the intervention program for the lower right leg always included lying leg curl in addition to leg extension on a machine. Another explanation may be the fact that the participants always exercised with high resistance (90-95\% 1RM). Therefore, this exercise also had to produce muscle strength during braking activity. And because the knee joint flexors are not strengthened as often as the extensors, they might have undergone a major adaptation.

For the leg curl exercise, we would assume that the transfer should manifest most into strength of hamstrings, knee joint flexors, during the concentric contraction, because flexors are dominant in this exercise (Evans, 2017, Delavier, 2015). In this case, the transfer results correspond to the assumption. The highest transfer was reflected from leg curl to the knee joint flexors at the concentric contraction (0.47). 
The greatest increase in strength (1RM) occurred in the leg curl exercise (right leg), by $31.96 \%$ (Figure 2). Corresponding to this, the highest percent increase in knee joint flexor force [Nm] of the right leg (at the eccentric contraction of $12.81 \%$, at the concentric contraction of $10.08 \%$ ) in Figure 3. Generally, we found higher power transfer from single-joint exercises. This could be due to more demanding technical requirements for multi-joint exercises as well as similarity of single-joint exercises and isokinetic dynamometer testing.

The limit of the study is the inclusion of only two test groups. The transfer would have a higher informative value if only one exercise was applied per group or if there was a separate test group for each exercise.

\section{CONCLUSION}

In summary, we have shown that from all selected exercises, there is a force transfer to selected muscles / muscle groups. According to our results, leg extension on a machine should be the most suitable exercise for strengthening knee joint extensors. Leg extension on a machine would also be the most appropriate exercise to strengthen knee joint flexors. Based on the results of this study, athletes should not expect such a large force transfer when training other exercises (leg curl lying, leg press, deadlift). Deadlift seems to be the least effective exercise for force transfer, where the force transfer value for knee joint extensors is only 0.16 and for knee joint flexors 0.12 . We would get other results if we focused on gain of force/strength, thus on the improvement of the results for a specific exercise (measured in 1RM) or for a specific limb (measured on an isokinetic dynamometer), instead on the force transfer. While the gain of strength (\% of 1RM) showed the highest progress in the exercise leg curl (right leg) and the lowest progress in the exercise leg extension on a machine (right leg), for the gain force we clearly see the highest increase in strength of the flexors of the knee joint on the right leg and the lowest increase in strength of muscles on the left leg, here it is specific with respect to a contraction. We see that the values of gain force correspond to the transfer values. The coach must always consider the purpose for which he is preparing strength training (rehabilitation, improvement of strength performance, preparation for a specific sport, etc.).

From the practical application point of view, this article brings to the strength and conditioning coaches a basic awareness of the suitability of using selected exercises. Trainers should know which exercise (type of contraction, movement speed, number of joints involved, etc.) is best suited for their purpose due to manage and plan the training process. This study provides important information of selected exercises that can help optimize the adaptation process.

\section{References}

Baechle, T. R., \& Earle, R. W. (2008). Essentials of strength training and conditioning. Champaign, IL: Human Kinetics. Delavier, F. (2015). Posilování: anatomický průvodce (2. rozšířené vydání). České Budějovice: Kopp.

Dovalil, J. et al. (2005). Výkon a trénink ve sportu (2. vyd). Praha: Olympia.

Evans, N. (2017). Bodybuilding - anatomie: váš ilustrovaný průvodce pro zvýšení svalové hmoty a vytvarování postavy (2. přepracované vydání). Brno: CPress.

Gentil, P., Fisher, J., \& Steele, J. (2017). A review of the acute effects and long-term adaptations of single-and multi-joint exercises during resistance training. Sports Medicine, 47(5), 843-855.

Chlápek, J. (2019). Vliv izolovaných a komplexních cvičení na silové projevy (Magisterská práce). Brno: Masarykova univerzita, $\mathrm{FSpS}$.

Issurin, V. B. (2013). Training transfer: scientific background and insights for practical application. Sports Medicine, 43(8), 675-694. 
Perič, T., \& Dovalil, J. (2010). Sportovní trénink. Praha: Grada.

Stoppani, J. (2016). Velká kniha posilování: tréninkové metody a plány: 381 posilovacích cviků (Druhé, přepracované a rozšírení vydání). Praha: Grada Publishing.

Zatsiorsky, V. M., \& Kraemer, W. J. (2014). Silový trénink: Praxe a věda. Praha: Mladá fronta. 